\title{
Paediatric Crossword Puzzle 10
}

\section{Manouri P Senanayake ${ }^{1}$}

Sri Lanka Journal of Child Health, 2010; 39: 156

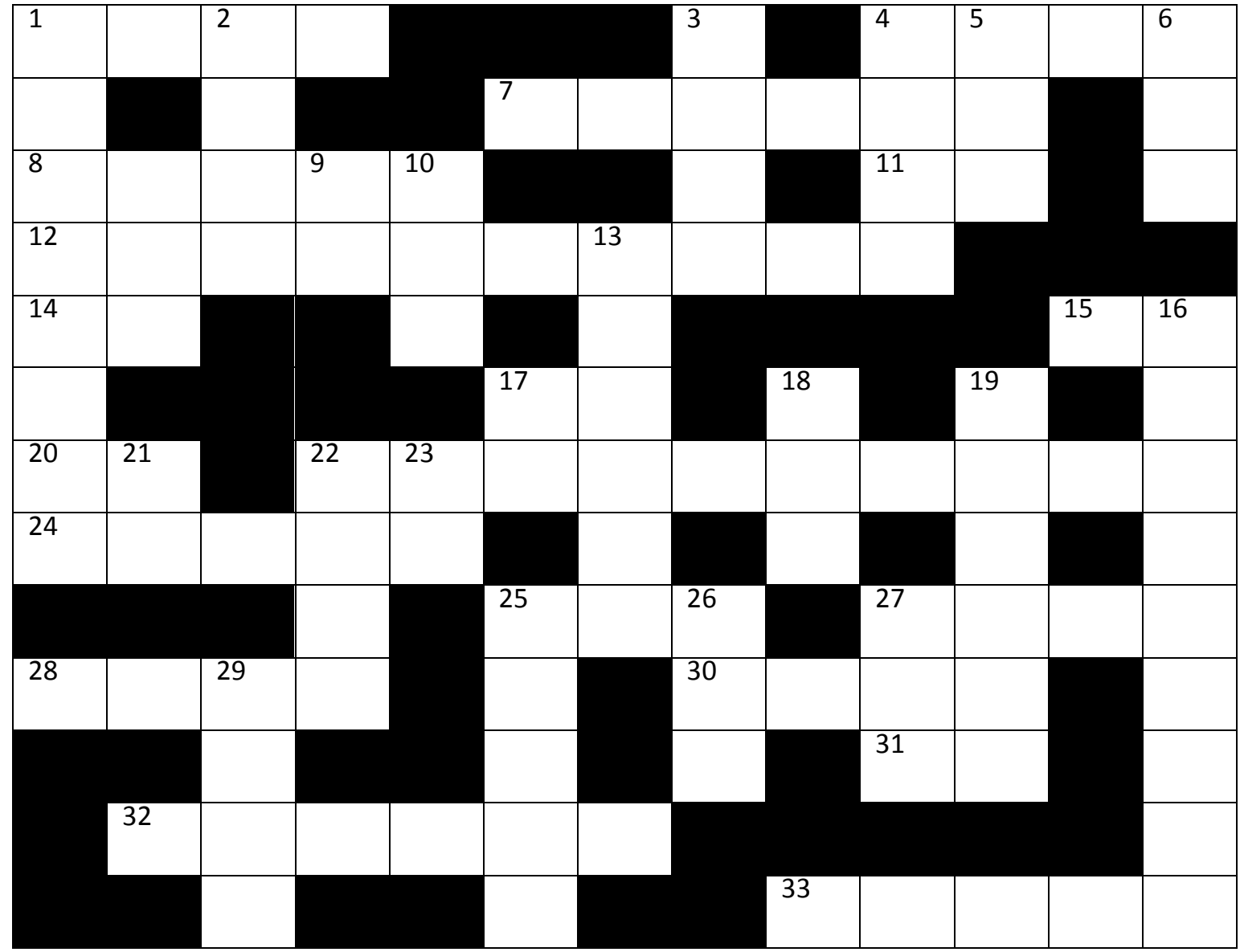

\section{Across}

1. a primitive reflex of clinical significance

4. null

7. physical sign suggesting meningeal irritation

8. spherical shaped bacteria

11. tube feeding ( $a b b r v)$

12 . causing obesity

14. Canadian province, the birthplace of the Canadian premier who was a medical doctor (abbrv)

15. autoantibody in systemic lupus erythematosus

17. gold standard for diagnosing gastro-oesophageal reflu disease

20. irradiation causing sunburn and skin cancer

22. assessment of hearing

24 . virus causing meningoencephalitis and pancreatitis

25. fluid that occupies the subarachnoid space (abbrv)

27. stains iron in bone marrow

28. cracked and reddened in Kawasaki disease

30. more common in African countries

31. congenital heart disease causing syncope

32. backflow

33. shiver

\section{Down}

1. a clinically significant irritant to newborn lung

2. staple diet

3. assessed by ferritin

4. reduces severity of diarrhoea

5. food item with a net protein utilization of nearly $100 \%$

6. an emollient available at home

9. two abnormal haemoglobins

10. component of the MD examination

13. reason for drug trials in children being rare

16. antiviral drug for HSV encephalitis

17. peritoneal dialysis (abbrv)

18. record electric activity of skeletal muscles

19. effect of excessive school related pressure

21. reflux from bladder to ureter ( $a b b r v)$

22. advanced paediatric life support

23. country that depicted Virginia Apgar on a stamp

25. stridor

26. adipose

27. vascular connection between pulmonary artery and aortic arch

29. ventilator setting in positive pressure mechanical ventilation

${ }^{1}$ Professor in Paediatrics, Faculty of Medicine, University of Colombo

See March 2011 issue for answers 